\title{
Bioética na América Latina: desafio ao poder hegemônico
}

Dora Porto

Resumo

Este trabalho propõe a discussão sobre pontos relevantes para a consolidação da bioética nos países em desenvolvimento, considerando, especificamente, as bioéticas latino-americanas. Busca estimular o debate acerca da construção de alternativa aos impasses decorrentes da ampliação do âmbito e foco da disciplina à dimensão social. Para isso, traça de modo sucinto o panorama da bioética nesses países, iniciando pela caracterização desse campo de estudo e sintetizando, em breve histórico, seu processo de construção. Em linhas gerais, descreve as principais conquistas das bioéticas desenvolvidas no contexto brasileiro e latino-americano, enfatizando, especialmente, sua aproximação aos direitos humanos, tomados como marcos regulatórios dos padrões éticos nas relações sociais. Apresenta, ao final, considerações críticas sobre o paradoxo implicado na adoção dos direitos humanos, buscando incentivar a reflexão acerca da bioética como ferramenta de luta contra as desigualdades que ainda marcam nosso continente.

Palavras-chave: Bioética. Direitos humanos. Sociedades. América Latina. Poder social. Controles informais da sociedade.

\section{Resumen}

\section{Bioética en Latinoamérica: desafío al poder hegemónico}

Este trabajo propone a discusión acerca de puntos relevantes para la consolidación de la bioética en los países en desarrollo, considerando, específicamente, las bioéticas Latinoamericanas. Busca estimular el debate acerca de la construcción de una alternativa al callejón sin salida que resulta de la expansión del alcance y enfoque de la asignatura a la dimensión social. Para ello, describe de manera sucinta el panorama de la bioética en estos países, a partir de la caracterización de este campo de estudio y que resume, en un breve historial, su proceso de construcción. En líneas generales describe los principales logros de las bioéticas desarrolladas en el contexto brasileño y latinoamericano, destacando, sobretodo, su acercamiento a los Derechos Humanos, considerados hitos regulatorios de los estándares éticos en las relaciones sociales. Presenta, al final, las consideraciones críticas acerca de la paradoja implicada en la adopción de los Derechos Humanos, tratando de fomentar la reflexión acerca de la bioética como herramienta de lucha contra las desigualdades que aún marcan nuestro continente.

Palabras-clave: Bioética. Derechos humanos. Sociedades. América Latina. Poder social. Controles informales de la sociedad.

\begin{abstract}
Bioethics in Latin America: challenge to hegemonic power

This paper proposes a discussion on relevant issues for the consolidation of Bioethics in developing countries, specifically considering the Latin American Bioethics. It seeks to encourage the debate on the construction of an alternative to the impasses resulting from the expansion of the subject scope and focus to the social dimension. For this, it succinctly outlines the viewpoint of Bioethics in these countries, starting from the characterization of this field of study and summarizing briefly its construction process. In broad terms, it outlines the main achievements of Bioethics developed in the Brazilian and Latin American context, especially emphasizing their approach to human rights, taken as regulatory milestones of ethical standards in social relations. It presents, in the end, critical considerations about the paradox implied in adopting Human Rights, seeking to encourage reflection about Bioethics as a tool to fight against the inequalities that still feature our continent. Key words: Bioethics. Human rights. Societies. Latin America. Social power. Social control, informal.
\end{abstract}

Doutora doraporto@gmail.com - Faculdade do Gama, Universidade de Brasília (UnB). Gama/DF, Brasil.

Correspondência

SQS 204, Bloco G, Apt 205 CEP 70234-070. Brasília/DF, Brasil.

Declara não haver conflito de interesse. 
"Uma minoria é considerada como tal quando constitui ameaça real ou imaginária para a maioria" *

A bioética é um campo de reflexão que questiona o poder, tanto nas relações entre profissionais e usuários na área da saúde quanto na dimensão social, especificamente naqueles aspectos concernentes às políticas públicas destinadas a promover a qualidade de vida. Ainda que também possa ser tomada como mais um dispositivo disciplinar de biopolítica, destinado a produzir, organizar e gerenciar o poder do status quo ${ }^{1} \mathrm{e}$, assim, reificar as estratégias de dominação das biotecnociências, seu papel de agente promotor de novos parâmetros na saúde é inegável.

É sob a égide da bioética que se instaura a reflexão acerca dos direitos individuais e coletivos em saúde, bem como a discussão baseada na noção de autonomia, que altera a milenar face paternalista da prática médica. Entretanto, se a construção da bioética é pontuada pela criação do neologismo a partir do crescente desenvolvimento da biotecnociência ${ }^{2}$, seu histórico revela que a ideia de bio, relacionada pelo senso comum à biomedicina, prevaleceu sobre a noção de ética na caracterização e classificação dessa modalidade de estudo, embora, em nenhum momento, a ética deixasse de ser a tônica das análises empreendidas.

É inegável, todavia, a proeminência do primeiro desses termos (bio) sobre o segundo (ética) nas representações coletivas sobre esse campo de estudos até porque, desde Darwin, a ciência, em geral, embasou a construção do conhecimento a partir de parâmetros biológicos (em maior ou menor grau), mesmo quando se dedicam a interpretar a vida em sociedade, como fazem as Ciências Sociais. Tais critérios imperam no imaginário científico e se disseminam por todas as sociedades (em níveis distintos), configurando-se modelo interpretativo das representações sociais sobre a ciência e seu status de locus da verdade. Esse processo de construção do conhecimento a partir da biologia consubstancia o surgimento de fenômenos como o da medicalização ${ }^{3}$, flagrado com ênfase variada nas sociedades de mercado, tanto do Oriente quanto do Ocidente, como apontam, no refluxo dessa posição hegemônica, tanto as Ciências Sociais quanto a Saúde Coletiva.

Apesar desse foco consagrado historicamente e fortalecido pelo valor atribuído aos diferentes ramos do conhecimento (notadamente na hierarquia valorativa que se estabelece entre as ciências biológicas e as humanidades, que faculta privilégio à primeira), a análise detalhada do termo mostra o quanto o campo da bioética é afeito à dimensão humana e relacional: a ética é um aspecto das relações humanas e diz respeito a valores atribuídos às práticas sociais; aos comportamentos individuais e coletivos e seu impacto no ambiente e na vida em sociedade. Tal caráter fica mais evidente diante da constatação lógica de que não há ética nem nas reações químicas nem nos processos fisiológicos. A ética é atributo - único e exclusivo - da vida humana ${ }^{4}$.

Por isso, estritamente falando, não se faz bioética em pesquisa de bancada nem em estudos de validação de medicamentos. A bioética aplica-se a essas investigações, contribuindo para que sigam critérios éticos que assegurem integridade física, psíquica, moral e social aos seres humanos direta ou indiretamente envolvidos. Para além da fase experimental, a disciplina também concorre para a reflexão ética sobre a prática biomédica ao discutir o efeito de um novo medicamento ou exame na vida social, como, por exemplo, o caso dos anticoncepcionais, ansiolíticos e antidepressivos, bem como dos exames de DNA para teste de paternidade, que transformaram as moralidades que condicionam a vida social contemporânea.

A importância dessa constatação remete àquilo ainda hoje usualmente considerado bioética: um campo do saber relacionado apenas à biomedicina e à análise das consequências de suas descobertas na vida social. Tal acepção influencia diretamente a forma como se compreende a produção de conhecimento nesse campo e sua classificação no rol das áreas do conhecimento. Mas, na verdade, a bioética constitui espaço bem mais complexo de produção de saberes, que exige a integração do conhecimento de diferentes áreas para produzir as respostas que a realidade demanda.

O âmbito expandido da reflexão bioética, especificamente da bioética brasileira, põe em relevo essa confluência ao identificá-la campo transdisciplinar ${ }^{5}$ de produção de saberes onde as questões biomédicas constituem tema sobre o qual se debruçam as ferramentas teóricas e metodologias das diversas áreas, que se estendem da Engenharia Ambiental às Humanidades, perpassando a Filosofia, Direito, Ciências Sociais, Pedagogia e Teologia, além das Ciências da Saúde e Medicina. Da interface surge um tipo de reflexão singular, que se define como campo de produção de saberes à medida que expõe uma situação, analisa os fenômenos observados e compara os elementos identificados nesse processo, produzindo aporte conceitual próprio, destinado a subsidiar teorias e práticas nessas áreas contributivas. A bioética 
utiliza os discursos das distintas áreas que se acercam ao campo e incorpora seus marcos conceituais, com eles dialogando para produzir uma análise de caso, a etnografia do conflito ético, identificado nas práticas de saúde ou na vida social (tomada de forma abrangente, considerando não só os aspectos relacionados às práticas na saúde, mas ao processo saúde/adoecimento na dimensão coletiva).

A partir desse processo antropofágico ${ }^{6}$ de apropriação e elaboração do conhecimento das áreas contributivas a bioética produz um saber que é apresentado a essas áreas na forma de reflexão sobre suas práticas, o que lhes permite aplicar as diretrizes éticas que dele emanam no processo de transformação da realidade social (quer na área da saúde ou dimensão coletiva). É em decorrência do resultado produzido nesse processo reflexivo (e antropofágico), que estabelece a possibilidade de conduzir efetivamente à transformação na realidade pela ação das áreas envolvidas, que a bioética pode ser caracterizada como ética aplicada. Sem essa interface não seria um campo de criação de saberes, restringindo-se a ser mais uma área de produção do conhecimento.

O processo de produção do saber em bioética, que se estabelece pelo consórcio de distintas áreas no mesmo campo de reflexão, é viabilizado pelo fato da reflexão bioética se consubstanciar a partir do exemplo, de uma situação na qual se manifesta um conflito, ao qual a análise bioética aplica a casuística ${ }^{7}$. Assevere-se, porém, que para a bioética a identificação do conflito pode decorrer da evidência (sua manifestação concreta) ou da suspeita, que pode ser detectada como existência de um conflito silencioso, no qual uma das forças em oposição ainda não tenha alcançado poder para se manifestar ou que tal manifestação não seja contundente o suficiente para ecoar na esfera coletiva.

Tal acepção hodierna da bioética pode parecer estranha (e frequentemente parece) a todos os que se acostumaram à identificação unívoca entre bioética e principialismo e à discussão direcionada unicamente às novas tecnologias e procedimentos introduzidos na área biomédica. Para reduzir o hiato entre as duas concepções e cumprir sua função precípua de fomentar a discussão transdisciplinar e plural, muitos estudiosos do campo (especialmente na América Latina) vêm trabalhando para libertar-se (de fato) da tutela dessa classificação unilateral de âmbito e temática ${ }^{8-65}$, amparados desde 2005 pelo reconhecimento da dimensão social da disciplina na Declaração Universal sobre Bioética e Direitos Humanos, da Unesco ${ }^{66}$.

\section{Breve histórico da bioética}

Originalmente cunhado nos Estados Unidos na década de 70, o termo "bioética" procurava designar a necessária interface entre as ciências biológicas e a reflexão humanista, no intuito de estabelecer parâmetros para lidar com os problemas ambientais e as descobertas em biotecnociência, que já se desenhavam na ocasião ${ }^{67}$. A acepção mais difundida consorciou a bioética à área biomédica, especialmente à Teoria Principialista ${ }^{68}$, cujos marcos conceituais (beneficência, não maleficência, autonomia e justiça) acabaram identificados como " $a$ " bioética ${ }^{69}$. Esta perspectiva primeva, sob a qual se disseminou mundialmente o termo, implicou que os conceitos norteadores do principialismo se tornassem sinônimo desse campo de estudos e a área biomédica fosse considerada seu único âmbito legítimo de atuação ${ }^{70}$.

Ao abrigo desse marco as temáticas discutidas focavam-se nas descobertas biotecnológicas e em sua aplicação pela Medicina. Com isso, a bioética adquiriu um caráter "exótico" para o senso comum, que a associava às "novidades" científicas que surgiam: os transplantes cardíacos, a fecundação assistida e a genômica, mesmo porque os conflitos e problemas decorrentes dessas descobertas predominavam entre os temas discutidos por aqueles que se dedicavam à disciplina. O foco da bioética, então, convergia para o impacto sobre as moralidades dos tratamentos e procedimentos recém-descobertos, os quais, geralmente, eram aplicados na perspectiva individual, contribuindo para obnubilar a dimensão coletiva na análise ética dos processos saúde/adoecimento.

No primeiro desses temas, os transplantes, a discussão ética girava em torno da caracterização da morte pela criação do conceito de morte encefálica, que substituiu a noção clássica associada à parada cardíaca. Essa definição transferiu o local da morte no corpo do coração para o cérebro, que, assim, se consolidou (também no nível fisiológico) como a sede dos processos que caracterizam (e permitem) o existir. Ao estabelecer critérios técnicos e éticos para definir a morte e amparar os procedimentos envolvidos nos transplantes, a transferência do locus da vida deu origem a toda outra gama de conflitos, relacionados aos estados de morte cerebral, às técnicas de ressuscitação e manutenção da vida orgânica, bem como àqueles decorrentes da anencefalia, que acabou relacionada à problemática do aborto - obviamente, naquelas sociedades, como no Brasil, onde o abortamento ainda é visto sob a moralidade da sacralidade da vida e não da quali- 
dade de vida e dos direitos humanos das mulheres, alheio, portanto, à dimensão da saúde pública ${ }^{29}$.

A temática da fecundação assistida gerou discussão em múltiplas fontes: as técnicas de inseminação, os bancos de esperma e de óvulos, a gravidez de substituição (barriga de aluguel) desafiaram os pressupostos morais envolvidos na definição dos laços de parentesco e noções de família. Esses conflitos espalharam-se por todas as sociedades que passaram a fazer uso dessas técnicas, haja vista que em todos os países as leis reguladoras das relações de parentesco na vida social não eram capazes, ao menos até então, de responder à nova teia relacional inaugurada pelo ineditismo desses procedimentos.

Nesse contexto, a genômica teve papel crucial, pois possibilitou atribuir-se paternidade consanguínea de modo inequívoco, contribuindo ainda mais para alterar as noções tradicionais de família e parentesco. A ideia de clonagem (com o inefável componente de imortalidade) e suas várias derivações, relacionadas à criação artificial de órgãos para transplantes e às novas terapêuticas nessa especialidade, como no caso do transplante de medula, por exemplo, tiveram papel fundamental na consolidação do que era entendido como bioética - que a princípio se debruçou sobre os conflitos derivados do uso de todas essas novas técnicas, abrindo campo para a discussão e confronto entre os parâmetros morais vigentes nas sociedades; a moralidade e normas inerentes à prática profissional na área da saúde; e a dimensão legal, tutora do ordenamento social. Na dimensão restrita à biomedicina, a bioética que emergiu nesse período inicial introduziu o questionamento sobre o poder individual na relação médico-paciente (que se estende em maior ou menor grau para as outras categorias profissionais de saúde), com a ferramenta do paternalismo. Problematizava também o poder de escolha na relação entre usuário e profissional nos serviços de saúde no que tange a testes e tratamento, com o conceito de autonomia ${ }^{71}$.

A ideia de paternalismo decorre da interpretação hegemônica sobre a responsabilidade do médico (que "não pode ser presumida") ${ }^{72}$ sobre a escolha do que é melhor para tratar "seu" paciente. Neste caso, o argumento provém da gênese da construção do conhecimento médico, do fato dessa formação profissional conferir àqueles que se dedicam a tal ocupação um saber diferenciado quanto à anatomia e fisiologia, bem como sobre patologia, o que, em contrapartida, cobra do detentor desses conhecimentos responsabilidade sobre o seu uso em prol do bem do outro, que recorre a seus serviços. A crítica ao paternalismo, implicada no principialismo, levou ao questionamento da assimetria consolidada no exercício desses papéis, resignificando a dinâmica das práticas em saúde ${ }^{73}$.

A autonomia (conceito incorporado à área médica pela bioética principialista) ${ }^{73}$ refere-se à capacidade e direito do usuário de exercer a escolha quanto a receber ou não receber tratamento, na clínica ou na pesquisa. Na discussão da autonomia os principais argumentos associavam-se à dupla imposição que recai sobre essa escolha para quem procura o serviço; a qual decorre tanto do estado de saúde do "paciente" 25 quanto da informação sobre riscos e benefícios de que dispõe o "usuário" para a tomada de decisão, discussão que transita precipuamente pela beneficência e não maleficência no acesso ao diagnóstico, mas que em alguns casos, extrapolando o âmbito clínico, caminha em direção à dimensão social mediante os conceitos de igualdade/desigualdade, dos quais deriva a equidade, aproximando-se da noção de justiça. Ressalte-se ainda que, quanto à autonomia do usuário na clínica e na pesquisa, atualmente a argumentação divide-se de forma polar: direito de receber e de não receber tratamento; e direito de participar ou não de um teste.

Sob o efeito da crítica ao principialismo focada no modus operandi das práticas biomédicas, na clínica e na pesquisa, a bioética tornou-se mais abrangente, começando a incorporar como parâmetros para discussão da ética nas práticas da área da saúde ideias pautadas em outros valores. $\mathrm{Na}$ bioética brasileira ${ }^{15}$ pode-se apontar especialmente aqueles propostos para responder aos conflitos em saúde na dimensão social, como vulnerabilidade e vulneração; proteção ${ }^{20-28}$; igualdade; e equidade ${ }^{18,33-38}$ - que de maneira geral são tendência em toda a América Latina $49,51,52,55,56,58,59$. Ressalte-se que além das propostas próprias dos países em desenvolvimento outras perspectivas também propõem esses marcos conceituais ${ }^{8,60-65}$. Entretanto, apesar dessas tentativas de expandir a discussão bioética à dimensão social, os parâmetros principialistas e o foco biomédico continuam sendo mais significativos em termos de quantidade de estudos acadêmicos e artigos científicos.

A ênfase no principialismo pode ser atribuída a diversos fatores inter-relacionados, dos quais nomeamos quatro que parecem ter maior relevância: 1) característica histórica da formação do campo a partir da área biomédica; 2) área de formação da considerável maioria dos pesquisadores (Biologia, Ciências da Saúde e Medicina, na qual os princípios hipocráticos adotados na clínica são parte da 
formação profissional); 3) facilidade de transpor os parâmetros relacionais da deontologia médica (beneficência, não maleficência e justiça) à bioética principialista, que acrescentou "apenas" a noção de autonomia ${ }^{73}$; ou, por fim, 4) o fato do ambiente relacional restrito da clínica e da pesquisa propiciarem a aplicação dos parâmetros bioéticos principialistas com maior facilidade do que se pode conseguir frente a complexidade das variáveis que causam impacto na realidade social.

A indiscutível importância da discussão bioética em torno das novidades biomédicas não impediu que com o tempo seu escopo se revelasse insuficiente para dar resposta aos conflitos relacionados aos processos saúde/adoecimento na dimensão coletiva ${ }^{8}$. Tal insuficiência tornou-se significativamente problemática nos países onde as condições sociais (econômicas e sanitárias) mostravam-se deficitárias para grande parte da população ${ }^{36-38}$. Nessas circunstâncias, a possibilidade de acesso à saúde não era minimamente distribuída entre os diversos segmentos e grupos, deixando imenso contingente à margem não apenas das descobertas transformadoras da biotecnociência, mas, principalmente, do acesso à saúde, considerado condição básica de cidadania. Vale notar que nessa época o parâmetro para definir saúde já deixara de ser ausência de doença, ampliando-se para qualidade de vida.

Sob tal questionamento, que no Brasil foi bandeira para o movimento da Reforma Sanitária e base para a criação do Sistema Único de Saúde (SUS), surgiram iniciativas para contextualizar o debate bioético às distintas realidades dos países em desenvolvimento. Os pesquisadores descontentes com a ferramenta principialista ${ }^{10,11}$ voltaram sua atenção ao resgate dos conceitos da saúde coletiva, bem como aos que emergiam dos movimentos sociais ${ }^{16,18,26-28}$, na tentativa de responder aos conflitos que surgiam da então recente reforma na atenção à saúde, proposta pelo SUS, associada à nova concepção de saúde ${ }^{74}$.

As iniciativas para construir perspectivas autóctones para a bioética nesse período acentuam a divergência em relação à perspectiva estadunidense ${ }^{12,33,42-45}$, questionando o principialismo - identificado como check-list normativo ${ }^{13}$ - e seu foco nas práticas curativas. $\mathrm{O}$ individualismo inerente ao modelo principialista começou a ser problematizado mediante consideração de que punha de lado o questionamento ético sobre os juízos morais que influenciam a saúde na dimensão coletiva e condiciona a produção da saúde e do adoecimento. Nesse sentido, é apropriado creditar à bioética o papel de dispositivo voltado a produzir corpos dóceis para servir às estratégias de poder ${ }^{1}$.

Atualmente, as ferramentas teóricas e conceituais para os estudos em bioética na dimensão social ainda estão sendo delineadas, mas a questão da desigualdade social entre segmentos, grupos, populações e sociedades já foi identificada como cerne da reflexão na dimensão coletiva, principalmente no que tange ao acesso à saúde e à qualidade de vida. Acompanhado pela discussão ambiental ${ }^{32,75,76}$, esse marco teórico vem crescentemente apontando a linguagem dos direitos humanos como gramática conceitual propícia à bioética, em várias teorias e propostas para a análise da ética relacional e procedimental, nas dimensões coletiva e social ${ }^{8-65}$.

Assim, em forma resumida, pode-se afirmar que tanto no Brasil como em diferentes países latino-americanos a bioética congrega atualmente essas duas vertentes analíticas: a bioética clínica propriamente dita, que reflete também sobre os parâmetros norteadores para a ética em pesquisa envolvendo seres humanos, e uma ainda incipiente bioética social, que tenta definir e aplicar parâmetros éticos na discussão sobre os conflitos em saúde na dimensão coletiva.

\section{Bioética social e direitos humanos}

A noção de direitos humanos (DH) deve ser considerada ganho inequívoco para toda a humanidade, pois foi o que permitiu o surgimento da necessidade de garantir a todas as pessoas a mesma dignidade inerente. Pensar em termos de igualdade, desigualdade e diferença - para todos os seres humanos - é uma conquista do século $X X$, que advém da consolidação dessa noção.

Ao definir que todos os seres humanos são portadores de direitos e que estes são inalienáveis, as noções de direitos humanos abriram a possibilidade de que se pudesse aplicar à dimensão coletiva conceitos - como igualdade/desigualdade - desenhados para estimular maior divisão de poder entre os integrantes da coletividade, especialmente dentre aqueles que questionam a autoridade tradicional. Esses conceitos e a ideia de maior simetria que carregam revelaram-se fundamentais para equacionar as práticas sociais e as moralidades que tradicionalmente condicionam a divisão do poder entre populações, segmentos e grupos.

Esse marco universal permitiu que todos os que não desfrutam dos mesmos direitos tradicionalmente garantidos ao "Homem" (ao qual se referiam 
originalmente os $\mathrm{DH}$, conforme o primeiro título da Declaração de 1948) ${ }^{77}$ pudessem perceber que algo estava errado, já que os direitos humanos e a dignidade a eles inerente deveriam se estender a todos os seres humanos, sem exceção, não podendo restringir-se a pessoas do sexo masculino, adultas, brancas, de classe média ou mais alta, que preferencialmente vivessem nas sociedades ocidentais $\mathrm{e}$ partilhassem valores e cultura desses contextos ${ }^{74}$. É provável, inclusive, que a tomada de consciência quanto a esta concepção horizontal tenha sido o que possibilitou que em todo o mundo mulheres, jovens, populações negras, bem como as populações tradicionais (como são chamadas as minorias étnicas e culturais no contexto dos DH), começassem a pensar sobre as desigualdades históricas que as vitimavam e, posteriormente, sobre as diferenças em sua visão de mundo que julgavam necessário preservar para manter sua identidade.

A noção de direitos humanos cresceu ao longo do século XX nas sociedades ocidentais, ampliandose do direito à vida do indivíduo ao direito à qualidade de vida das populações, incorporando nesse último parâmetro a discussão cultural que, a partir de meados da década de 60 , passou a ser considerada elemento essencial a essa qualidade, especialmente para grupos ou segmentos com características socioculturais distintas ${ }^{78-84}$. Embasados em noções ainda não totalmente delineadas do que fossem tais direitos, os movimentos sociais que emergiram ou se fortaleceram a partir da segunda metade do século XX questionaram a autoridade das pessoas mais velhas, o poder de decisão do pater familias, o poder regulador dos homens sobre as mulheres, a primazia das pessoas brancas sobre as negras, bem como sobre as de diferentes grupos étnicos. Em todos esses questionamentos os argumentos voltavam-se à divisão mais equânime do poder entre indivíduos, segmentos e grupos, tal como proposto pelos $\mathrm{DH}$. Sublinhe-se que, ao menos a princípio, esses movimentos (cujas propostas mudaram os padrões de sociabilidade no século XX) não teciam suas bandeiras utilizando formalmente os instrumentos de direitos humanos como fio condutor, embora essas noções fossem subjacentes às reivindicações por maior igualdade e assimetria nas relações sociais.

Dentre esses movimentos obtiveram mais êxito na promoção de mudanças efetivas de comportamento nas sociedades ocidentais aqueles cujos marcos podiam ser aplicados individualmente, ou seja, os que se referiam aos papéis e valor social atribuídos aos indivíduos de diferentes segmentos etários e de gênero: jovens, adultos e idosos; mulheres e homens. Por dizerem respeito a grande número de pessoas em qualquer país do mundo, suas ideias eram generalizáveis e podiam ser aplicadas à maioria dos indivíduos, repercutindo mundialmente e produzindo a transformação da realidade social com maior facilidade. Pela mesma razão, os movimentos que se referiam a parcelas da população, como os relacionados à racialização e etnia, não obtiveram resultados tão unânimes no contexto global.

Deixando de lado considerações acerca das relações de poder sob o estado de exceção, bem como as travadas pelo uso da força bruta, se pode depreender deste processo que a transformação da realidade tenderá a ocorrer à medida que um valor (e o comportamento a ele atribuído) for partilhado pela maioria da mesma maneira que a manutenção do status quo (e das moralidades que o sustentam) se efetiva pela ação da maior parte dos indivíduos na coletividade. Assim, em um ou em outro caso, quando os valores que orientam o comportamento individual encontram eco na dimensão coletiva tornam-se realidade objetiva, consubstanciando a reprodução da moralidade a eles associada.

A constatação sobre a ação da maioria na dinâmica de reprodução ou transformação da realidade social evidencia que o tamanho da população (que demanda a manutenção ou alteração do status quo) está diretamente relacionado à sua possibilidade de efetivar o que se pleiteia. Quanto mais próximos da maioria em um conjunto social estiverem os indivíduos que reivindicam a mudança da realidade, maior será a chance de efetivá-la para toda a população. Deve-se atentar, todavia, que o poder da maioria na consolidação da realidade é uma força em si, que pode atuar em qualquer direção, para promover transformações voltadas à igualdade e simetria ou para produzir ainda mais desigualdade, preconceito e discriminação ${ }^{4}$.

Tomando a história recente para ilustrar casos em que se podem observar resultados positivos na transformação da realidade social rumo a maior simetria, isso fica nítido em relação aos movimentos baseados em cunho etário, das décadas de 50 e 60, que se propagaram e impuseram nas sociedades ocidentais pelo aumento de pessoas nessa faixa etária, decorrente do baby boom. Também se pode observar a força da maioria nos movimentos de mulheres, que somam um pouco mais da metade dos habitantes do planeta. Acrescente-se a forte motivação das mulheres para acolher uma mudança voltada a melhorar seu status e poder, pois não obstante às diferenças culturais em cada sociedade, a subalternidade feminina era, ao menos então, universal ${ }^{85}$. 
Além de ser escolha da maioria também influencia a transformação da realidade a permeabilidade estrutural do segmento ou grupo que reivindica determinado valor social (e comportamento a ele associado). Ou seja, a dispersão na teia social da população que demanda a permanência ou a mudança de determinado valor social também tem relação direta com a possibilidade de efetivá-la na dimensão coletiva. No caso dos movimentos de jovens naquelas décadas, porque havia pessoas nessa faixa etária em todos os estratos da sociedade. Mais ainda do que ocorreu com os jovens, os movimentos de mulheres alcançaram resultados notáveis porque a população feminina também está dispersa por toda a teia, considerando-se nesse caso não apenas as diferentes classes sociais, cor de pele e etnia (classificando no último aspecto especificamente a dimensão cultural), mas abarcando, inclusive, todas as faixas etárias, variável que (obviamente) não se aplica aos movimentos de jovens. No caso dos movimentos de mulheres acrescente-se ainda o fator de permanência temporal em torno do mesmo conjunto de reivindicações, pois a condição feminina está associada no imaginário à constituição física, de forma quase indelével, sendo, portanto, marcada como "verdade biológica inerente", que confere à condição de ser mulher cunho mais permanente do que ser jovem, situação por natureza transitória.

Em decorrência de referirem-se à maioria em distintas sociedades e permearem os diversos estratos dessas sociedades, os componentes identitários dos movimentos sociais da segunda metade do século XX - etário e de gênero - lograram mudanças expressivas na realidade social das sociedades ocidentais, no que diz respeito à transformação dos lugares de poder tradicionalmente consolidados. Esses dois movimentos consorciados atuaram inclusive no sentido de questionar e solapar a tradicional autoridade do pater familias, colaborando ainda mais para alterar a divisão de poder tradicional. Disso se deduz que a permeabilidade, bem como a permanência, são fatores que propiciam o alcance das reivindicações propostas pela maioria. Note-se, inclusive, que a permeabilidade é o fator que impede (ou dificulta) o acirramento dos conflitos inerentes ao processo de transformação de um valor ou moralidade, já que dilui na malha social a estigmatização do segmento ou grupo que propõe a mudança. Seria impossível, por exemplo, colocar na década de 60 todas as mulheres no gueto ou os jovens em campos de concentração, da forma como foram segregados pelo poder hegemônico outros grupos no passado.
Entretanto, se é inolvidável o ganho para o conjunto da humanidade trazido pelos $\mathrm{DH}$ não se pode desprezar uma consequência adversa da aplicação da perspectiva universalista a eles intrínseca, que se manifesta nos casos em que os segmentos ou grupos que reivindicam essas garantias não estão dispersos na estrutura social nem constituem a maioria. Ao contrário dos exemplos anteriores, observa-se a forte tendência para eliminar as vozes dissonantes, como se deu em relação às populações nativas americanas na época em que se iniciou a ocupação europeia (chamada de "descobrimento") ou como ocorreu em pleno século XX na África e Europa, quando a retirada dos governos coloniais e regimes totalitários, respectivamente, propiciou massacres dos grupos minoritários. Pode-se também constatar a tendência a isolar real ou simbolicamente os segmentos e grupos minoritários, aumentando o preconceito e a discriminação pela segregação, como aconteceu em relação aos judeus desde a Idade Média, por exemplo, ou como se reproduz atualmente pela construção de muros para separar os povos latinos das terras estadunidenses e os palestinos de Israel. A história mostra ainda que em tais situações o que tende a ocorrer, "no melhor dos casos", é a busca pela "adequação" aos parâmetros morais hegemônicos num processo forçado de assimilação de valores e aculturação - como o que até hoje marca a dinâmica da colonialidade ${ }^{6,78-84,86}$ na América Latina. Mesmo que se desconsidere a parte desses exemplos extraída de períodos históricos nos quais os $\mathrm{DH}$ não estavam esboçados, restam as situações hodiernas que continuam ocorrendo mundialmente e ilustram as tendências humanas para lidar com as diferenças.

Em relação ao momento atual, no qual o conjunto das nações já começa a incorporar os parâmetros igualitários dos direitos humanos, a dificuldade em aplicar esses valores aos grupos e segmentos diferentes ocorre porque, ainda que se destinem a salvaguardar os direitos dos povos, os $\mathrm{DH}$ devem - necessariamente - expressar-se por meio de documentos pautados pelo consenso entre as nações, delineando, portanto, apenas um conjunto de mínimos essenciais ${ }^{87}$. Firmados em instrumentos internacionais voltados à saúde, educação, economia, direitos civis, políticos, trabalhistas e ambientais, por exemplo, os direitos humanos não respondem particularidades do contexto social ou atendem à especificidade cultural dos diferentes povos e subconjuntos da população dos Estados-parte, mesmo naqueles casos em que esses instrumentos destinem-se a assegurar direitos específicos. 
A necessidade de que possam abranger a grande maioria dos casos nos quais se detecta violação de direitos humanos e de alcançar consenso entre os países signatários sobre as melhores providências a serem tomadas, essencial a uma estrutura anárquica por excelência, como as Nações Unidas, dificulta que se possam identificar situações particulares, como as apontadas pelos movimentos sociais em cada nação. Ao estabelecer padrões do que sejam as necessidades intrínsecas à qualidade de vida para todos os seres humanos, que possam ser aplicados pelos governos nacionais a distintas realidades, os $\mathrm{DH}$ permitem indiretamente a manutenção da assimetria social que estrutura a dinâmica dessas mesmas sociedades. Dado que são por natureza incapazes de impedir a reprodução de assimetrias na dinâmica interna dessas sociedades, sua aplicação não inibe a imposição de parâmetros que ignoram diferenças, especialmente as de cunho cultural, sobrepondo indiscriminadamente os valores da maioria.

Isso ocorre porque a aplicação das recomendações firmadas no âmbito das Nações Unidas cabe aos governos dos países, que devem adequar essas disposições gerais a sua realidade social. O que muitas vezes acontece é que a dinâmica hierárquica de cada sociedade, consolidada historicamente, dificulta que grupos minoritários e tradicionais consigam efetivamente reivindicar adequações a seu caso específico, como podemos visualizar no Brasil com parte significativa dos povos indígenas, mesmo quando articulados em torno de suas reivindicações.

Dadas essas contingências, que marcam a implementação dos $\mathrm{DH}$ nas políticas públicas, esses instrumentos são muitas vezes identificados por essas minorias como mais uma forma de imposição vertical de valores da maioria e, por isso, rechaçados. Assim se tem o exemplo de como a transformação da realidade pela assunção aos valores da maioria pode não estar necessariamente significando alteração do status quo para as minorias, mas sua manutenção. Ainda que sob argumentos pautados na igualdade proposta pelos $\mathrm{DH}$, a reprodução da assimetria acaba por fortalecer processos impositivos e dinâmicas sociais verticais entre grupos majoritários e minoritários, contribuindo para que os direitos culturais, relacionados às noções de identidade e pertencimento, sejam olvidados e os direitos humanos rejeitados como um todo, identificados como mais um elemento de reprodução da dinâmica colonial.

A dificuldade das minorias em consolidar reivindicações autóctones, especialmente as relacio- nadas a diferenças decorrentes de valores de ordem cultural, que se manifesta em quase todos os setores abarcados pelos DH (educacional, jurídico, econômico, ambiental), é especialmente forte na Saúde. Na dimensão individual isso decorre das circunstâncias nas quais a área é chamada a atuar na vida social, no processo de adoecimento que implica em vulneração física, psicológica e social do indivíduo, bem como no enfrentamento de circunstâncias desfavoráveis de assimetria, inerentes às práticas profissionais e aos sistemas de saúde, como apontado pela bioética principialista. No Brasil, como em toda a América Latina, acrescentem-se as dificuldades de acesso aos sistemas e a precariedade dos serviços.

Na dimensão coletiva, no âmbito da bioética social, a dificuldade pode ser atribuída à crescente influência do fenômeno da medicalização na construção das verdades do imaginário social, relativo aos processos saúde/adoecimento. Decorrente da soma dos aportes tecnológicos na área da saúde e do poder da indústria farmacológica e de equipamentos, esse fenômeno vem consolidando o uso pelo senso comum de categorias médicas para identificar e classificar as práticas sociais e hábitos de vida, condicionando a "transformação" dos comportamentos e das emoções em patologias. O fenômeno da medicalização tornou-se hegemônico nas sociedades ocidentais, estendendo-se da estética às condições sanitárias, sempre mediado por interesse econômico. Assim, quase tudo que "deve" ou não ser feito decorre de razões de "saúde", associada à qualidade de vida e ao paradigma biomédico. Ao constituir-se discurso hegemônico, a medicalização contribui para esfumar os limites da prática clínica, vez que esta se confunde com o próprio discurso que legitima a construção do conhecimento e a reprodução do comportamento na dimensão coletiva.

Identificado como qualidade de vida o paradigma biomédico se estende por todos os aspectos da vida social. Sob esse marco, que é piéce de résistance dos $\mathrm{DH}$ na área da saúde, os imperativos gerados pelo fenômeno da medicalização acabam confundidos com as diretrizes propostas pelos direitos humanos para minimizar (ou eliminar) a desigualdade social e garantir (por meio da equidade) qualidade de vida para todos. Por essa associação indébita o paradigma biomédico é imposto de maneira generalizada, reforçando a assimetria de poder entre os interlocutores nos casos em que as particularidades culturais das minorias não correspondem aos parâmetros estabelecidos pela maioria. Pelo fato de contrastarem com o paradigma hegemônico, as reivindicações dos segmentos e grupos minoritários 
acabam deslegitimadas; classificadas como ignorância, desvio ou aberração pela maioria, que, como visto, é quem tem força para impor seus parâmetros de verdade à dinâmica social.

Torna-se fundamental, então, apontar a falha da bioética no que diz respeito à implementação dos $\mathrm{DH}$, tanto no Brasil quanto nos demais países em desenvolvimento, ainda que sejam indiscutíveis os ganhos conceituais advindos da consagração da Declaração Universal sobre Bioética e Direitos Humanos ${ }^{64}$, que legitimou a aplicação da disciplina na dimensão social. Entretanto, persiste a lacuna entre a reflexão bioética empreendida no âmbito acadêmico e as demandas dos movimentos sociais no tocante a conferir visibilidade e pleitear legitimidade às reivindicações decorrentes de uma realidade cultural específica, que (ao menos potencialmente) pode colocar em xeque os pressupostos do paradigma hegemônico.

Por permanecer focada na área da saúde (e, portanto, subsumida ao argumento da medicalização que a impregna) e olvidar, em grande medida, a própria transdisciplinaridade essencial a sua constituição como campo de produção de conhecimento, a bioética social ainda não alcançou plenamente seu objetivo de mediar os conflitos éticos em saúde na dimensão coletiva. Por basear seus argumentos apenas em padrões que reproduzem a moralidade da maioria, mesmo que estes sejam moldados pelos $\mathrm{DH}$, a bioética social deixa de questionar a autoridade nos casos em que o paradigma biomédico entra em conflito com os parâmetros culturais de grupos e segmentos minoritários ou, até mesmo, com as predisposições individuais daqueles que fazem parte da dinâmica social da maioria, mas, paradoxalmente, não compactuam todos os valores ou hábitos de vida prescritos pelo paradigma biomédico.

Em decorrência da reprodução dessa dinâmica vertical, que marca a bioética social atualmente implementada a partir do âmbito acadêmico, se reproduz o modus operandi hierárquico em detrimento da horizontalidade proposta pelos $\mathrm{DH}$. Por isso, a crítica às posições hegemônicas, próprias dessas novas perspectivas, não produz o efeito esperado, haja vista que tais abordagens não conseguiram - efetivamente - delinear ferramentas capazes de congregar as diferenças nos marcos de horizontalidade dos $\mathrm{DH}$; os valores de assimetria que impregnavam a visão de mundo da área biomédica são reproduzidos nas tentativas de analisar e mediar conflitos em saúde na dimensão coletiva. Isso decorre, em grande medida, também do afastamento entre a academia e os movimentos sociais, do desconhecimento da primeira dos discursos nativos e dinâmicas locais e da dificuldade da segunda em lidar com a força transcendente do mercado globalizado, que é atualmente o princípio articulador das dinâmicas sociais nas sociedades ocidentais. Nessas circunstâncias é impossível deixar de apontar que as bioéticas sociais brasileiras e latino-americanas ainda não conseguiram atuar de forma a propiciar a superação das dinâmicas verticais, descontextualizadas e que estigmatizam a implementação dos marcos dos direitos humanos nas políticas públicas para os grupos minoritários.

\section{Considerações finais}

Apesar de ser possível constatar que as bioéticas brasileiras e latino-americanas estão buscando construir os marcos para uma reflexão ética em saúde na dimensão coletiva, também se observa que ainda não conseguiram de fato transcender a dinâmica dessa "herança" para perceber e refletir sobre a diferença, no que concerne a garantir direitos que fujam à verticalidade inerente ao modelo biomédico.

Para transcender esse quadro precisamos fortalecer a transdisciplinaridade buscando a simetria de discurso entre as distintas áreas que contribuem para o campo da bioética, o que permitirá relativizar a herança hierárquica inerente ao paradigma biomédico, que condiciona a aplicação vertical dos $\mathrm{DH}$ pelas bioéticas sociais. Também devemos fomentar o diálogo com os movimentos sociais, que permitirá incorporar a reflexão autóctone e as categorias que emanam dessas lutas, objetivando ampliar a visibilidade e legitimidade das reivindicações decorrentes de uma realidade cultural específica, bem como atualizar as categorias e conceitos da própria bioética social.

Neste momento em que se inicia a maturação das bioéticas sociais, brasileiras e latino-americanas, tais desafios precisam ser encarados e discutidos para que se possa prosseguir na consolidação de parâmetros éticos aplicáveis à dimensão coletiva. Só assim a bioética do nosso continente estará efetivamente questionando o poder e fomentando a cultura crítica e libertária.

*A epígrafe é tradução livre de fala da personagem principal do filme A Single Man (EUA;2009), dirigido por Tom Ford e baseado em livro homônimo de Christopher Isherwood. 


\section{Referências}

1. Lysaught MT. Docile bodies: transnational research ethics as biopolitics. J Med Philos. 2009 ago;34(4):384-408. DOI: 10.1093/jmp/jhp026 (acesso 15 jun. 2014).

2. Schramm FR. Paradigma biotecnocientífico e paradigma bioético. In: Oda LM, editora. Biosafety of transgenic organisms in human health products. Rio de Janeiro: Fiocruz; 1996. p. 109-27.

3. Corrêa MV. Novas tecnologias reprodutivas. Limites da biologia ou biologia sem limites? Rio de Janeiro: Editora UERJ; 2001. p. 23-33.

4. Porto D. Bioética, poder y justicia: la acción por los derechos humanos. III Congreso Internacional de la Redbioética Unesco para América Latina y el Caribe. Bioética en un continente de exclusión: de la reflexión a la acción. Bogotá: Universidad El Bosque/Unesco/Universidad Nacional de Colombia; 23-26 de noviembre de 2010. [Internet] Disponível: http://www.bioeticaunbosque. edu.co/memoriastercercongresoredbioetica.pdf (memórias p. 144-69).

5. Garrafa V. Multi-inter-transdisciplinaridad, complexidad y totalidad concreta en bioética. In: Garrafa V, Kottow M, Saada A. Estatuto epistemológico de la bioética. México; Unam/Redbioética; 2005. p. 67-85.

6. Justo L. Una mirada antropofágica sobre la justicia distributiva. Mímeo; 2010.

7. Junges JR. Bioética como casuística e como hermenêutica. Rev. Bras. Bioética. 2005; 1(1): 28-44.

8. Berlinguer G. Bioética cotidiana. Brasília: Editora UnB; 2004.

9. Berlinguer G. Em direção à globalização da saúde. Rev. Bras. Bioética. 2007; 3(4):437-50.

10. Garrafa V. Dimensão da ética em saúde pública. São Paulo: Faculdade de Saúde Pública USP/ Kellogg Foundation; 1995.

11. Schramm FR. A terceira margem da saúde. Brasília: Editora UnB; 1996.

12. Garrafa V, Oselka G, Diniz D. Saúde pública, bioética e equidade. Bioética. 1997; 5(1): 27-33.

13. Diniz D, Guilhem D, Garrafa V. The bioethics in Brazil and the principialist theory. Bioethics. 1999; 13(3-4): 243-8.

14. Anjos MF. Bioética, abrangência e dinamismo. O Mundo da Saúde. 1997; 21(1):11-9.

15. Siqueira JE, Porto D, Fortes PAC. Linhas temáticas da bioética no Brasil. In: Anjos MF, Siqueira JE, organizadores. Brasília /Aparecida: Sociedade Brasileira de Bioética/Ideias e Letras; 2007. p. 161-84.

16. Anjos MF. Teologia da libertação e bioética. In: Privitera S. Dicionário de bioética. Aparecida: Santuário; 2000.

17. Anjos MF. Bioethics in a liberationistic key. In: Dubose E, Hamel R, O’Connell L, organizadores. A matter of principles? Ferment in U.S. Bioethics. USA: Trinity Press Int/Valley Forge; 1994. p. 13047.

18. Anjos MF. Bioética nas desigualdades sociais. In: Garrafa V, Costa SIF, organizadores. A bioética no século XXI. Brasília: Editora UnB; 2000. p.49-65.

19. Anjos MF. Dignidade humana em debate. Bioética. 2004; 12(1):109-14.

20. Schramm FR, Kottow M. Princípios bioéticos en salud pública: limitaciones y propuestas. Cad Saúde Públ. 2001; 17(4): 949-56.

21. Kottow M. Bioética de protección. In: Tealdi JC, director. Diccionario latinoamericano de bioética. Bogotá: Unesco/Redbioetica/Universidade Nacional de Colômbia; 2008. p. 165-7.

22. Schramm FR. Informacción y manipulación: ¿cómo proteger los seres vivos vulnerados? La propuesta de la bioética de proteccion. Rev. Bras. Bioética. 2005; 1(1):18-27.

23. Schramm FR. Proteger os vulnerados e não intervir aonde não se deve. Revista Bras. Bioética. 2007; 3(3): 401-13.

24. Schramm FR. Bioética sem universalidade? Justificação de uma bioética latino-americana e caribenha de proteção. In: Garrafa V, Kottow M, Saada A, organizadores. Op. cit. p. 143-57.

25. Schramm FR. A saúde é um direito ou um dever? Autocrítica da saúde pública. Rev. Bras. Bioética. 2006; 2(2): 187-200.

26. Oliveira MF. Bioética: uma face da cidadania. São Paulo: Moderna; 1997.

27. Oliveira MF. Opressão de gênero, feminismo e bioética: algumas considerações para o debate. Mesa-redonda Gênero e Bioética. RAGCyT - Red Argentina de Gênero, Ciência y Tecnologia. Buenos Aires; 5 dez. 1998.

28. Oliveira MF. Feminismo, raça/etnia, pobreza e bioética: a busca da justiça de gênero, antirracista e de classe. In: Garrafa V, Pessini L, organizadores. Bioética: poder e injustiça. São Paulo: Loyola; 2003. p. 345-63.

29. Sandi SF, Braz M. As mulheres brasileiras e o aborto: uma abordagem bioética na saúde pública. Rev. bioét .(Impr.). 2010; 18(1): 131-53.

30. Braz M. Población. In: Tealdi JC, director. Op. cit.; 2008. p. 465-7.

31. Braz M, Raggio A, Junges R. Desafios globais e participação da bioética brasileira. In: Anjos MF, Siqueira JE, organizadores. Op. cit. p. 186-211.

32. Junges JR. A proteção do meio ambiente na declaração universal sobre bioética e direitos humanos. Rev. Bras. Bioética. 2006; 2(1): 21-38.

33. Garrafa V. Bioética, salud y ciudadania. Salud Problema y Debate. 1997; 9(16):26-33.

34. Garrafa V. Bioética fuerte: una perspectiva periférica a las teorias bioéticas tradicionales. Conferencia: $3^{\text {er }}$ Congreso de Bioética de América Latina y del Caribe. Panamá: Felaibe; maio/2000.

35. Garrafa V. Inclusão social no contexto político da bioética. Rev. Bras. Bioética. 2005; 1(2): 122-32. 
36. Garrafa V, Porto D. Intervention bioethics: a proposal for peripheral countries in a context of power and injustice. Bioethics. 2003; 17(5-6):399-416.

37. Garrafa V, Porto D. Bioética de intervención. In: Tealdi JC, director. Op. cit.; 2008. p. 161-4.

38. Porto D, Garrafa V. Bioética de intervenção: considerações sobre a economia de mercado. Bioética. 2005; 13(1):111-23.

39. Porto D, Tapajós A. Gênero, raça e bioética de intervenção. In: V Congresso Brasileiro de Bioética. Recife; 2004. p. 26. Anais.

40. Porto D. Tecnologia \& ideologia: os dois lados da moeda que produz vulnerabilidade. Rev. Bras. Bioética. 2006; 2(1):63-86.

41. Porto D. A moralidade da globalização. Brasília: Dora Porto, editora; 2009.

42. Fortes PAC, Zoboli ELCP. Bioética e saúde pública. São Paulo: Edições Loyola; 2003.

43. Fortes PAC. Control social. In: Tealdi JC, director. Op. cit.; 2008. p. 538-40.

44. Fortes PAC. Orientações bioéticas de justiça distributiva aplicada às ações e aos sistemas de saúde. Rev. bioét. (Impr.). 2008; 16(1):25-39.

45. Fortes PAC. As condições de vida, de trabalho e de saúde como "caldo de cultura" para a violência. Bioética 2004; 21(2): 113-9.

46. Barchifontaine CP. Humanismo y dignidad. In: Tealdi JC, director. Op. cit. p. 278-80.

47. Cassinelli H. La salud como derecho humano. In: Tealdi JC, director. Op. cit. p. 244-5.

48. Tealdi JC. Dignidade humana. In: Tealdi JC, director. Op. cit. p. 274.

49. Tealdi JC. Bioética y derechos humanos. Rev. Bras. Bioética. 2007; 3(3): 360-76.

50. Tealdi JC. Crímenes de lesa humanidad. In: Tealdi JC, director. Op. cit.; 2008. p. 282-4.

51. Kottow M. Bioetica: especialidad académica o movimiento social. Rev. Bras. Bioética. 2007; 3(3): 328-43.

52. Kottow M. Bioética pública: una propuesta. Rev. bioét. (Impr.). 2011; 19(1): 61-76.

53. Justo L. Investigación participativa. In: Tealdi JC, director. Op. cit. p. 361-3.

54. Pfeiffer ML. Vida, cuerpo y dignidad humana. In: Tealdi JC, director. Op. cit. p. 280-2.

55. Pfeiffer ML. Ética y derechos humanos: hacia una fundamentación de la bioética. Rev. Bras. Bioética. 2006; 2(3):281-98.

56. Candal LM. Hacia la construcción de una ética colectiva, pública u informada. Rev. Bras. Bioética. 3(3); 2007: 390-405.

57. Valenzuela JG. Dignidade humana. In: Tealdi JC, director. Op. cit. p. 277-8.

58. Codina PLS. La sociedad como sistema dinámico complejo. La Habana: Publicaciones Acuario; 2006.

59. Bergel SD. Responsabilidad social y salud. Rev. Bras. Bioética. 2006; 2(4): 443-67.

60. Singer P. Why we need to sep living now. Revista Bioética. 2009; 17(1): 9-11.

61. Häyry M, Takala T. Human dignity, bioethics and human rights. Developing World Bioethics. 2005; 5(3): 225-33.

62. Rendtorff JD. Basic ethical principles in European bioethics and biolaw: autonomy, dignity, integrity and vulnerability. Towards a foundation of bioethics and biolaw. Medicine, Healthcare and Philosophy. 2002; 5(3): 235-44.

63. Neves MCP. Sentidos da vulnerabilidade: característica, condição, princípio. Rev. Bras. Bioética. 2006; 2(2): 157-72.

64. Sané P. Aplicación de la declaración universal sobre bioética y derechos humanos. Rev. Bras. Bioética. 2006; 2(4): 437-42.

65. Saada A. La declaración universal sobre bioética y derechos humanos. Ampliación democrática para una sociedad más justa. Rev. Bras. Bioética. 2006; 2(4): 413-22.

66. Organização das Nações Unidas para a Educação, a Ciência e a Cultura. Declaração Universal sobre Bioética e Direitos Humanos. Unesco; 2005. Disponível: www.bioetica.catedraunesco.unb. br (acesso 14 fev. 2008).

67. Pessini L. Bioética das intuições pioneiras. Perspectivas nascentes aos desafios da contemporaneidade. Rev. Bras. Bioética. 2005; 1(3): 297-311.

68. Beauchamp TL, Childress JF. Princípios de ética biomédica. São Paulo: Edições Loyola; 2002.

69. Junges JR. Ética e consentimento informado. Cadernos de Ética em Pesquisa. Ministério da Saúde/Comissão Nacional de Ética em Pesquisa; 2000. p. 22.

70. Freitas $C B D$, Hossne WS. O papel dos comitês de ética em pesquisa na proteção do ser humano. Bioética. 2002;10(2): 129-46.

71. Beauchamp TL, Childress JF. Op. cit. p. 137-207.

72. Conselho Federal de Medicina. Código de Ética Médica. Parágrafo único, art. $1^{\circ}$, capítulo III Responsabilidade Profissional. Resolução CFM n 1.931/09. Publicada no DOU de 24 de setembro de 2009, Seção I, p. 90. Retificação publicada no DOU de 13 de outubro de 2009, Seção I, p. 173.

73. Siqueira JE. A bioética e a revisão dos códigos de conduta moral dos médicos no Brasil. Rev. bioét. (Impr.). 2008; 16(1): 85-95.

74. Porto D, Garrafa V. A influência da reforma sanitária na construção das bioéticas brasileiras. Rev. Ciênc. \& S. Col. 2011 mar; 16 (supl. 1). Disponível: http://dx.doi.org/10.1590/S141381232011000700002

75. Gutiérrez MOO. Ética Ambiental. III Congreso Internacional de la RedBioética Unesco para América Latina y el Caribe. Op. cit; 2010. [Internet] Disponível: http://www.bioeticaunbosque. edu.co/memoriastercercongresoredbioetica.pdf (Memórias p.118-23). 
76. Echeverri APN. Pensamiento ambiental en resonancias bio-ético-poéticas. III Congreso Internacional de la RedBioética Unesco para América Latina y el Caribe. Op. cit; 2010. [Internet] Disponível: http://www.bioeticaunbosque.edu.co/memoriastercercongresoredbioetica.pdf (Memórias p.1245).

77. Organização das Nações Unidas. Declaração Universal dos Direitos Humanos. Adotada e proclamada pela Resolução 217 A (III) da Assembleia Geral das Nações Unidas em 10 de dezembro de 1948. Disponivel: http://portal.mj.gov.br/sedh/ct/legis_intern/ddh_bib_inter_universal.htm (acesso 15 jun. 2014).

Quijano A. Coloniality of power, eurocentrism and Latin América. Nepantla: Views from South 1.3. 2000; 533-74. Disponível: http://www.unc.edu/ aescobar/wan/wanquijano.pdf (acesso 15 jun. 2014).

79. Lander E. Ciencias sociales: saberes coloniales y eurocéntrico. In: , editor. La colonialidad del saber: eurocentrismo y ciencias sociales. Perspectivas Latinoamericanas. Buenos Aires: Consejo Latinoamericano de Ciencias Sociales; 2000. p. 4-23. Disponível: http://bibliotecavirtual. clacso.org.ar/clacso/sur-sur/20100708034410/lander.pdf (acesso 15 jun. 2014).

80. Dussel E. Ciencias sociales: saberes coloniales y eurocéntrico. In: Quijano A, editor. Op. cit. p. 2433.

81. Mignolo WD. La colonialidad a lo largo y a lo ancho: el hemisferio occidental en el horizonte colonial de la modernidad. In: Quijano A, editor. Op. cit. p. 34-52.

82. Colombres A. El proceso de aculturacion. In: La colonización cultural de la America indígena. Buenos Aires: Ediciones del Sol; 2004. $2^{\mathrm{a}}$ ed. p. 57-96. (Serie Antropologica).

83. Columbres A. La hora del "bárbaro". Bases para una antropología social de apoyo. Buenos Aires: Ediciones del Sol; 1986. (Serie Antropologica).

84. Briones C. La aboriginalidad como forma de organizar las diferencias. In: La alteridad del cuarto mundo. Una descronstrución antropológica de la diferencia. Buenos Aires: Ediciones del Sol; 1998. (Serie Antropologica).

85. Rosaldo MZ, Lamphere L. Introdução. In: organizadores. A mulher, a cultura e a sociedade. Rio de Janeiro: Paz e Terra; 1979. p. 19.

86. Nascimento WF. Por uma vida descolonizada: diálogos entre a bioética de intervenção e os estudos sobre a colonialidade. [tese]. Faculdade de Ciências da Saúde/Universidade de Brasília/ UnB; 2010.

87. Casado M. A vueltas sobre las relaciones entre la bioética y el derecho. Rev. Bioét. (Impr.). 2011; 19(1): 15-28.

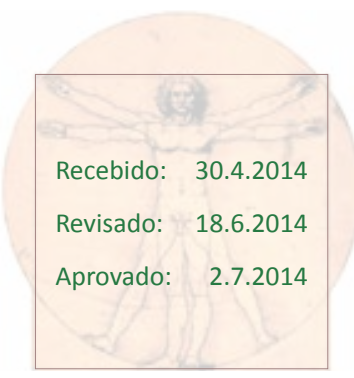

